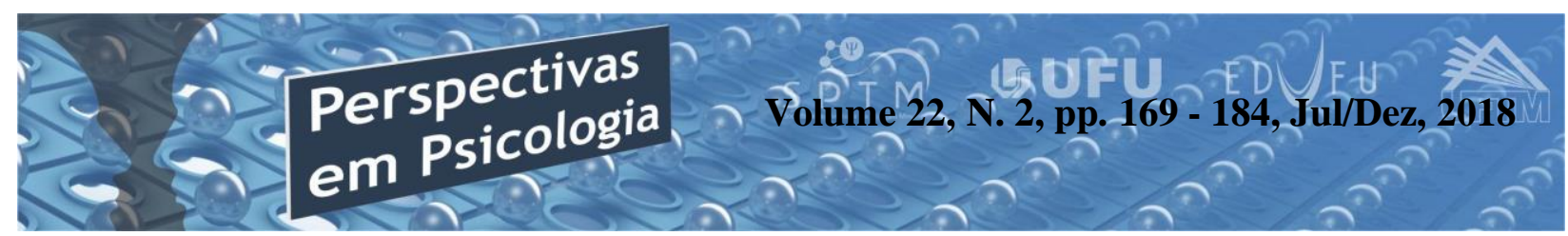

\title{
POR UMA (RE)DIMENSÃO ARTEFATUAL DA "PSIQUE HUMANA" - TEORIA ATOR-REDE E PSICOLOGIA
}

\author{
Idonézia Collodel-Benetti \\ João Paulo Roberti Junior \\ (Universidade Federal de Santa Catarina - UFSC, Florianópolis - SC)
}

\begin{abstract}
Resumo
A Psicologia tem a característica singular de rever com elevada frequência as suas próprias categorias analíticas e os seus preceitos teórico-metodológicos. Um desses momentos de questionamento vem das reflexões levantadas pela perspectiva dos Estudos Sociotécnicos ou Teoria Ator-Rede de Bruno Latour. Este ensaio, com delineamento qualitativo e de problematização teórica, tem como objetivo colocar em discussão uma série de estudos e debates que se têm realizado sobre a Teoria Ator-Rede e suas contribuições para a Psicologia. O foco será o modo como são tratadas as associações entre humanos e não humanos e as apreciações como o social, a rede, o sujeito/objeto. Assim, foram sistematizados alguns conceitos e princípios da perspectiva sociotécnica e de simetria generalizada. Incluiu-se um rastreamento dos trabalhos produzidos na Psicologia, a partir da perspectiva sociotécnica da Teoria Ator-Rede. Os resultados apontam para novas concepções da relação entre Psicologia e Teoria-Ator Rede.
\end{abstract}

Palavras-chave: psicologia; teoria ator-rede; simetria.

\section{Abstract \\ By an Artefactual (Re)Dimension of "Human Psyche": Actor-Network Theory and Psychology}

Psychology has a rather unique feature to review with a very rapid rate its own analytical categories and their theoretical and methodological precepts. One of those moments of questioning their own bases in recent years has raised the prospect of reflections or sociotechnical study by Actor-Network Theory of Bruno Latour. In this perspective, we note that now the emphasis is on social (understood as the human) whose most times it implied what we call social relationships is something that is established exclusively between humans and people. Now the emphasis is on technical (understood as the non-human), emphasizing the potential of machines and software, which most times it implied that the human is to these techniques, as if they alone would determine new forms of relationship between humans and constitution. From this realization that he began to seek the Actor-Network Theory (English, Actor-Network Theory or ANT) subsidies to give special treatment to the subjects of the humanities, the social and technical thinking symmetrically constituted as a network that decentralized agencies in their translation capacity.

Keywords: psychology; actor-network theory; symmetry. 


\section{Considerações Iniciais}

A Psicologia expressa nos dias atuais uma complexa rede de significações a respeito das mudanças e dos preceitos teórico-metodológicos que perpassem sua teoria. O estudo e a problematização de conceitos e de teorias, em Psicologia, se reverte para a construção e busca da qualidade de ação e intervenção ao qual a Psicologia é fadada. As teorias afirmam práticas e visões de mundos (Ferreira, 2010).

No entanto, todo o amparo, no qual a Psicologia constantemente se baseia, sugere uma subversão constante e necessária à Psicologia, tornando-a sempre um movimento contemporâneo. Este movimento "[...] é uma singular relação com o próprio tempo, que adere a este e, ao mesmo tempo, dele toma distâncias; mais precisamente, essa é a relação com o tempo que a este adere através de uma dissociação e um anacronismo" (Agambem, 2009, p. 59). Aqueles que coincidem muito plenamente com a época, que em todos os aspectos aderem perfeitamente, não são contemporâneos porque, exatamente por isso, não conseguem vê-la, não podendo manter fixo o olhar sobre ela.

\footnotetext{
${ }^{1}$ Para tanto, mostra-se significativa a preposição de Skinner: "[...] as teorias afetam a prática. Uma concepção científica do comportamento humano dita
}

É neste sentido que o presente trabalho é um convite para pensar a Psicologia através de um movimento contemporâneo. Para tanto, exige-se ser contemporâneo, também, os textos e os autores que circundam a teoria; de forma que o contemporâneo nunca é atual [porque já é parte de minha análise], portanto criar uma inatualidade sobre o que se está fazendo, pensando nas discussões que serão propostas, significa adotar a postura contemporânea na Psicologia, não apenas percebendo-a ao escuro do presente e que nele aprende e se volta à luz, mais sim dividir e interpolar o tempo, colocando sempre em constante relação com o atual (Agambem, 2009).

Essa postura leva a pensar em como a Psicologia tem se voltado contra a sua própria herança (Ferreira, 2010). Significa que, antes de pensar em atuar, o psicólogo deve pensar em sua teoria ${ }^{1}$. O percurso ao qual irá alvitrar o presente trabalho é desafiador e, antes de tudo, é um arriscar-se em público dado o cruzamento metodológico e teórico que será proposto. Esse processo adotará como referencial teórico metodológico a Teoria do AtorRede (TAR - Teoria Ator-Rede em Português ou ANT - do inglês Actor-

uma prática, a doutrina da liberdade pessoal outra. Confusão na teoria significa confusão na prática." (1974, p.23) 
Network-Theory), ou também denominada de sociologia das associações (Latour, 2012).

Deste modo, o presente trabalho tem como objetivo colocar em discussão uma série de estudos e debates que se têm realizado sobre a Teoria Ator-Rede e suas contribuições para a Psicologia, com foco no modo como são tratadas as associações entre humanos e não-humanos $\mathrm{e}$ as apreciações como o social, a rede, o indivíduo, o sujeito/objeto. Para estas considerações serem pensadas nestes caminhos, este estudo sistematizará alguns conceitos e princípios da perspectiva sociotécnica e de simetria generalizada. Posteriormente, incluir-se-á um rastreamento dos trabalhos produzidos na Psicologia, a partir da perspectiva sociotécnica da Teoria Ator-Rede, em especial o pensamento nos desdobramentos teóricos de uma dimensão artefatual da ação e da psique.

Deste modo, a discussão teórica irá permitir que a Psicologia (re)pense concepções metodológicas que até então não eram possíveis em seu campo. Salientase que, embora Bruno Latour não estabeleça em sua literatura reflexões sistematizadas da Psicologia, encontramos em seu trabalho moções e pontes que podem ser estabelecidas com diversos ramos do conhecimento. Todavia, a "[...] sua forma de pensar os Estudos Científicos permite refletir a Psicologia sobre novos prismas" (Tsallis, Ferreira, Moraes \& Arendt, 2006, p. 59).

Embora grande parte da literatura de Bruno Latour já se encontra traduzida para a Língua Portuguesa (Latour, 1994; 1997; 1998-a; 1998-b; 2000; 2001; 2002; 2012), muitos conceitos e conhecimento desta ainda não são conhecidos no meio acadêmico e principalmente na Psicologia. Portanto, apresentar inicialmente alguns conceitos demonstra-se importante na medida em que auxilia o leitor a situar-se na literatura. Contudo, ao longo da explanação alguns conceitos poderão estar já engendrando discussões com a Psicologia, portanto a sistematização se dará ao longo da explanação dos conceitos.

A Psicologia encontra nessa topologia heterogênea da rede sociotécnica uma matriz fértil para pesquisas acerca de processos e objetos que tradicionalmente permaneciam ora no exterior do seu campo de investigação, ora desprovidos de uma abordagem conceitual e metodológica pertinente (Bruno, 2010). Em linhas gerais, a ANT (TAR) tem-se afirmado como um saber que rejeita a descrição do mundo "moderno". Latour (2005) concebe a modernidade como um conjunto de práticas que, em muitas medidas, não coincidem com a teoria; na forma que os modernos 
conceberam uma realidade bifurcada entre natureza e cultura. Porém, “[...] as práticas de purificação, que se buscava na modernidade a fim de se obter meios pelos quais os coletivos (separadamente humanos e não-humanos) pudessem se ampliar e progredir, só foram possíveis pelo contrário: a mistura deles". (Rifiotis, Segata, Máximo e Cruz, 2011).

A ANT propõe rever conceitos e divisões modernas, tais como a noção de coletivo, ator, rede, fetiche, agência etc. Esta última chama a atenção para a dimensão artefactual da participação dos objetos técnicos na gênese dos processos cognitivos. Conceber a ação como mediação (Latour, 1994; 2012) permite não definir um acontecimento por causas e consequências, mas um deslocamento de objetivos e ações. Conceber, então, a ação deslocada permite não definir de antemão uma relação de causa e efeito, mas considerar o deslocamento da ação, buscando a participação dos não-humanos na ação.

Assim, como já afirmado, dado que esta abordagem não é de uso comum, serão apresentados alguns debates e conceitoschave que irão habilitar e mediar o diálogo com a Psicologia. Portanto, o que mais amplamente se iniciou na negação de dicotomias entre natureza e cultura e que está atualmente sob a denominação de
Teoria Ator-Rede em Bruno Latour, faz (re)pensar discussões para o presente artigo.

\section{Teoria Ator-Rede}

"Por onde andavam os micróbios antes de Louis Pasteur?" (Latour, 2011, p. 175), perguntou-se certa vez o sociólogo Bruno Latour. Apesar de aparentemente simples, a pergunta traz à tona uma controvérsia paradoxal presente naquilo que chamamos de "produção científica" ou mais amplamente, de "produção de conhecimento": a invenção. Os micróbios sempre estiveram lá, responder-se-ia facilmente à Latour; no entanto, eles nunca existiriam sem Pasteur. A dificuldade está em perceber que Pasteur faz existir os micróbios - ele os inventa, no sentido de produzir condições para que eles passem a existir de jure, já que de facto eles sempre existiram.

Em termos resumidos, Pasteur dá status aos micróbios. Ainda em continuidade a esta discussão, Latour, em outro trabalho (Latour, 2001), faz uma distinção entre "ciência" e "pesquisa" sobre a qual ele justifica a sua insistência no uso do "faz" (faire), em oposição à palavra "feito" ou "fato" (fait). Segundo ele, nessa pequena proposição controversa, aparece, sobretudo, uma ambiguidade etimológica que há muito já foi revelada por Gaston Bachelard: o fato científico. Um fato tanto 
pode designar "algo que se fabrica" (que pode ser feito), como algo que "não pode ser fabricado, pois já está dado (que está feito, pronto, acabado)" -e nessa segunda concepção, um dado (fato) é algo sólido, palpável, e se impõe ao pesquisadorcientista, pois já está feito e se antecipa à análise.

O paradoxo aparece então na possibilidade do fato ser aquilo sobre o qual a ciência "se fabrica", pois estuda o fato, como aquilo que é fabricado pela ciência, pois ela pode fazer ofato enquanto lugar de pesquisa e descoberta. Nesse caso, Latour volta-se para a pesquisa, que segundo ele é o momento, em termos simplificados, onde a ciência está em ação - ou seja, onde ela partiu de fatos (coisas dadas, ou feitas), que podem ou não constituir algum tipo de paradigma, para chegar a algum novo fato (um feito, fabricado), que pode se constituir em um novo paradigma (Latour, 2001).

Levando em consideração algumas diferenciações entre ciência (science) e pesquisa (recherche), Latour caracteriza a primeira com as palavras "certa", "fria", "sem ligação com política ou sociedade", onde o "fato é aquilo que não se pode discutir" pois já está feito, enquanto que a segunda, a pesquisa, ele caracteriza com palavras como "incerta, arriscada", "quente", "numerosamente ligada à política e à sociedade", onde o "fato é aquilo o que é construído" ou que está sendo feito (Latour, 2001). Nesse caso, interessa aqui, ao se propor um estudo sobre a pesquisa e a ciência em Ciências Humanas, descrever e analisar pesquisa (recherche), no sentido daquilo que está "sendo feito", que está em ação, e não apenas descrever e analisara ciência feita (science), no sentido daquilo que já foi estabelecido - interessam assim, as ligações, os interesses e tudo o mais que Latour (2001b, p. 15) considera como "três difficile à établir ${ }^{2} \%$.

Desde os anos de 1960, em especial com a publicação de Estruturas das Revoluções Científicas (Kuhn, 1962), o estudo das ciências deixou de ser privilégio de metodólogos das Ciências Naturais, para passar a se constituir em campos de estudo das Ciências Humanas. Além de Thomas Kuhn, nomes como os de Gaston Bachelard, Imre Lakatos, Karl Popper, Michel Foucault, Bruno Latour, ou Isabelle Stengers, para citar apenas alguns, dedicaram-se ou ainda têm se dedicado ao que amplamente se pode chamar de "estudos das ciências", e é possível dividilos entre os que Latour classificou como aqueles que estudam a "ciência" estabelecida, e aqueles que estudam "a

\footnotetext{
2"Muito difíceis de estabelecer" (Tradução nossa).
} 
ciência em curso de ação", incluindo-se entre estes, o próprio Latour (Latour, 2001).

As discussões constituidoras da Teoria Ator-Rede (ANT - Actor-Network Theory) passam a tomar corpo a partir de meados da década de 1970, quando David Bloor desenvolve um programa de investigações sociais cujo objetivo central residia em analisar o que faz certos grupos de cientistas, em diferentes épocas, selecionar certos aspectos da realidade como objeto de estudo. Ele chamou isso de Programa Forte (Bloor, 2009). Isso tornou possível considerar o trabalho dos cientistas, ou mesmo a ciência e a tecnologia, como algo construído sob certos aspectos internos da própria comunidade científica e, igualmente, certos aspectos ditos, então, sociais e históricos (Bijker \& Pinch, 1989; Bloor 1999, 2009; Callon, 1989).

Então, David Bloor sugere para tal empreito, no âmbito do que se conhecia por Science Studies (estudos científicos ou sociologia das ciências), um princípio programático da simetria, que consistia basicamente em reconhecer que os mesmos tipos de causas devem servir como modos de explicação. Mesmo que estes modos sejam eles estabelecidos (crenças valorizadas), como também aqueles que não vigoravam no interior das ciências (crenças rechaçadas), não antecipando vencedores ou vencidos, nem os tomando como essencialmente diferenciados (Bloor, 2009; Freire, 2006; Law, 1999, 2004).

É com vistas a uma crítica a essa postura, que autores como Bruno Latour e Michel Callon estendem esse princípio teórico-metodológico formulado por David Bloor às controvérsias entre natureza e sociedade, que também deveriam ser tratadas sob um mesmo plano, sob um princípio de simetria generalizada, uma vez que, para eles, não haveria de um lado um mundo das coisas em si em contraposição a um mundo dos homens; para eles, ambos seriam efeitos de redes. Tais redes não seriam, por isso, compostas pelos mesmos elementos, mas sim poderiam ser investigadas/descritas da mesma maneira, sob os mesmos termos.

Em resumo, sob o princípio de simetria generalizada, natureza e sociedade, sujeito e objeto, etc. poderiam ser descritos simultaneamente, sem que se fizesse necessário recair o peso da descrição sob um dos supostos pólos, o que resultaria na permanência de um esquema assimétrico. Destarte, a simetria generalizada amplificaria o potencial do princípio programático de simetria, uma vez que esta última ainda tomava "o social" como um lugar privilegiado para se discutir as ciências e a natureza.

Este também foi um dos caminhos traçados para a constituição de um modo de se pensar em uma antropologia simétrica, 
que reivindicasse uma simetria total entre humanos e não-humanos, ultrapassando as grandes divisões entre natureza e cultura, entre sujeito e objeto, tão em voga hoje. Dessa maneira, do ponto de vista dos Science Studies, quando se está falando de eletrodos de pilhas, filamentos de lâmpadas incandescentes, da bactéria do antraz ou dos peptídeos do cérebro, não se está falando de domínios exclusivos das técnicas ou das ciências, tampouco da natureza dessas coisas em si, mas do seu envolvimento com coletivos compostos de sujeitos humanos e não-humanos, constituídos/transformados em processos contínuos de tradução.

Neles, é possível deslocar objetivos, desestabilizar entidades e, acima de tudo, gerar sempre novos efeitos. Assim, o termo tradução na Teoria Ator-Rede (Latour 1999, 2005, 2012; Law 2006; Freire, 2006; Ziemkendorf, 2007) deve ser lido como o processo de transformação que determinado fato, feito ou ator vai sofrendo e fazendo sofrer.

No entanto, é preciso traçar breves considerações sobre o que cabe no rótulo "ator-rede". A noção de ator não pode ser confundida com o sentido tradicional de "ator social", uma vez que um ator é tudo que age, deixa traço, produz efeito no mundo, podendo se referir a pessoas, instituições, coisas, animais, objetos, máquinas, ou tudo isso simultaneamente:
“[...] empregar a palavra "ator" significa que jamais fica claro quem ou o quê está atuando quando as pessoas atuam, pois o ator, no palco, nunca está sozinho ao atuar" (Latour, 2012, p. 75).

Assim, sublinhe-se que a actancialidade não seria aquilo o que o ator faz - pois a ação seria distribuída, não seria univocal, não caberia na identificação do ator-em-si: “[...] por definição, a ação é deslocada. A ação é tomada de empréstimo, distribuída, sugerida, influenciada, dominada, traída, traduzida" (Latour, 2012, p. 76). Daí a importância de se assinalar que se estaria tratando aqui de um ator-rede e não simplesmente de "um ator" $e$ de "uma rede", em separados.

Há agências, as mais diversas, atuando simultaneamente no mundo. E, assim, como intuito de se evitar o equívoco de se atribuir exclusivamente ao humano a agência, é comum encontrarmos a utilização do termo semiótico actante (no mesmo sentido de ator), ou seja, qualquer coisa que atue, ou que mova alguma ação (Akrich \& Latour, 1992). Corroborando para esse sentido, há ainda a utilização de uma voz verbal presente entre os gregos, a "middle voice", que não seria nem passiva, nem ativa, e que à falta em outras línguas, poderia ser traduzida como o que "faz fazer" ("faire faire" no francês, ou "to make one do", no inglês) - ela permite distribuir 
as certezas do que ou de quem está agindo (Latour, 1999).

A noção de rede também começou a se tornar um problema à medida que a emergência da WorldWideWeb demandou estudos específicos. Ela ficou diretamente "colada" à ideia de internet. Na cibernética, uma rede se refere aquilo que transporta informações por longas distâncias, mantendo-a intacta, pura, sem quaisquer deformações. Algo consideravelmente distante do projeto latouriano, interessado justamente nos efeitos, nas traduções, nos desvios, nos "chiados" delas. Enfim, o que está em proeminência são os fluxos, as multiplicidades de conexões, e não o estável, o igual.

Anteriormente a isso, aparecia outro equívoco que era o de compreender rede com aquela "ideia torta" de "vamos flexibilizar as instituições rígidas, pontiagudas", algo que aliviasse o peso das noções de instituição, sociedade, ou Estados-Nação: “[...] 'down with rigid institutions', they all say, 'long live flexible networks"” (Latour, 1999, p. 15). Uma rede não poderia ser definida por superfícies, tampouco por seus limites externos; antes, sim, o foco está nos agenciamentos, nas alianças entre elementos heterogêneos (humanos e não humanos).

$\mathrm{Ou}$ seja, a rede por si só pode também se constituir como um ator, uma vez que ela produz efeitos, que ela não é uma entidade fixa, logo, não é o objeto de análise. A análise deve recair na capacidade que essas redes têm em redefinir, ou transformar os seus componentes (internos e externos): de modo resumido, interessam os efeitos das redes. Pensar com elas, não pensar elas. Assim, a rede como método é criação - ao me utilizar delas para descrever um mundo, o que resulta é um mundo por elas criado - o mundo não está organizado em rede, a rede organiza o nosso modo de ver o mundo. Trata-se daquilo que, à maneira que Lévi-Strauss, entendia os mitos na sua ciência do concreto; elas equivalem a uma modalidade discursiva que organiza a explicação do mundo, das coisas, da realidade. A rede faz o mundo, não por seus conteúdos, mas pelos seus potenciais de diferenciação e multiplicação.

\section{A dimensão Arte fatual da "Psique": humanos e não-humanos na Psicologia}

Notadamente a Psicologia tem como objeto de sua análise os humanos, dotados de consciência e intencionalidade. Porém, esta concepção torna-se menos evidente quando consideramos não-humanos na gênese da ação e de constituição da cognição. Neste sentido, analisar o processo de rede e o processo cognitivo da ação com relação a humanos e não-humanos marca incertezas quanto à natureza da ação. 
A noção de rede concebe caminhos ao qual se pode pensar a natureza da ação, pensando o social não em termos de ação, mas também de produção. Pergunta-se assim: quais os vínculos concebidos entre humanos e não-humanos? Quais efeitos que tais vínculos produzem na gênese do processo cognitivo? O social, então, deixa novamente de se tornar um modelo operativo-descritivo e analítico para pensar o processo que interfere na constituição dos fatos e da cognição.

Considerar os não-humanos é antes de tudo considerá-los que possuem “[...] agência, produzem efeitos no mundo, modificam nossas ações, redefinem nossa cognição" (Moraes, 2005, p. 7). Os estudos e afirmações de Latour auxiliam a perceber e repensar as informações e explicações postas sempre a priori na Psicologia [e muitas vezes como descritivoqualificadores], oferecendo e garantindo modelos transcendentais e ontológicos que são dados de antemão e não auxiliam a conhecer os vínculos entre humanos e nãohumanos.

A Psicologia irá exprimir na sua análise, o resultado da modernidade: humanos de um lado e não-humanos de outro (Latour, 1994; 2012). Isso significa que esta concepção modernista "[...] conferia aos sujeitos liberdade e autonomia enquanto considerava os objetos como regidos pela necessidade e determinação" (Pereira, 2010, p. 47). Essa análise também é égide sobre outras áreas do saber, como a sociologia, por exemplo, que considera a autonomia do indivíduo esmagada através das estruturas sociais.

Assim, assumir o papel e conceber que o objeto da Psicologia é fabricado, distribuído na rede e articulado entre humanos e não-humanos é conceber que nada está dado de antemão. A tarefa da Psicologia será a de buscar condições objetivas e/ou subjetivas do conhecimento, acompanhando as alianças entre humanos e não-humanos, onde se faz e se constitui a subjetividade de uma psique humana. Assim,

Os não-humanos, até então estudados como passivos, submetidos às ações humanas, são eles também atores que devem ser levados em conta por uma psicologia considerada como estética da cognição. Assim, longe de ser referida ao par sujeito-objeto a cognição passa a ser entendida a partir das articulações entre humanos e nãohumanos. Cognição híbrida, mestiça longe, portanto, das distinções que marcaram as pesquisas em psicologia: sujeito $\mathrm{X}$ objeto, indivíduo $\mathrm{X}$ sociedade, psicologia social $\mathrm{X}$ cognitiva (Moraes, 2005, p. 9). 
Trata-se, portanto, de não avaliar simetricamente as constituições entre humanos e não-humanos, mas sim da Psicologia acompanhar, no âmbito de sua prática e pesquisa, o modo como se dá a associação entre humanos e não-humanos. É “[...] ultrapassar a dupla separação moderna entre humanos e os não-humanos, defendendo que se dê igual importância de tratamento para a produção tanto dos primeiros quanto dos segundos" (Freire, 2006, p. 49).

A ANT apresenta-se como uma alternativa para a concepção da ação dos indivíduos, pois “[...] nem a suposta liberdade do indivíduo tomado isoladamente nem $o$ ambiente, $o$ inconsciente e a sociedade, como estruturas causais" (Pereira, 2010, p. 47) satisfazem a análise da explicação da ação de um ator ${ }^{3}$. Um ator é aquele que age sobre outro ator, provocando neste, modificações. Portanto, tudo age: tanto humanos quanto nãohumanos. Considera-se, neste sentido, uma dimensão que concebe e refuta as oposições entre interior e exterior, mental e material, sujeito e objeto. A dimensão artefatual desloca a atenção para a participação dos objetos técnicos da gênese do processo cognitivo (Moraes, 2005).
Para exemplificar este processo, temos o exemplo da arma na composição de práticas (Bonamigo, 2010). A posição é que não podemos prever o que pode acontecer quando se junta uma pessoa e uma arma, pois, como visto, não há uma essência do sujeito ou do objeto. Assim, no encontro entre uma pessoa e uma arma, um novo objetivo pode ser constituído, onde há uma nova ação a ser pensada, deslocando-se em pensar que "[...] havendo a criação de um novo vínculo que modifica tanto a pessoa quando a arma" (Bonamigo, 2010, p. 172). Então, os artefatos reais são sempre partes de instituições hesitantes em sua condição mista de mediadores (Latour, 2001), transformando-se e alterando-se, não como um todo ou como entidades dicotômicas entre sujeito-objeto, mas pensando na metonímia da arma, como um "sujeitoarma" (Bruno, 2010).

Assim, uma concepção mentalista ou ambientalista nos convida a mudar as mentes, sentimentos ou ambientes dos homens, ao invés de refletir as ações postas no mundo em que vivem. Afinal, é tentador acreditar que não são armas que matam e sim mentes e contextos agressivos (Skinner, 1974, adaptado). Portanto as ações, ora são localizadas nos indivíduos, como se fizesse parte de sua natureza, ora são localizadas na

diferenças, desvios, transformações na distribuição da ação numa rede sociotécnica e na fabricação do mundo.” (Bruno, 2010, p. 11).
${ }^{3}$ Latour $(2001$; 2012) considera ambos humanos e não humanos como atores. Conceber um ator é conceber "[...] tudo que tem agência, que produz 
sociedade, entendendo-se com uma construção social (Bruno, 2010). Pensar, portanto que a arma me inscreve em uma série de relações, que não eram possíveis sem ela, é considerar que os não-humanos possuem agência e que produzem efeitos no mundo, modificando nossas ações e nossa psique humana. O social não pode ser entendido como algo que antecede nossas práticas, ou mesmo como um modelo operativo-descritivo das ações, mas algo que é (re)tecido na rede de articulações.

A Teoria Ator-Rede se revela, assim, com um dispositivo teóricometodológico de análise que é capaz de enfrentar o desafio contemporâneo de levar em consideração a multiplicidade e heterogeneidade das ações dos indivíduos, considerando, na sua gênese, os nãohumanos, conduzindo à descrição das relações que se estabelecem entre os elementos heterogêneos que compõem o fluxo da ação, sem fixar em algum lugar as ações dos humanos. As relações são estabelecidas em um espaço fluido e constante, que em lugar da essência busca uma "existência arriscada" (Bonamigo, 2010, p. 177), para as ações e análise destas na Psicologia. Portanto, o melhor que se pode para caminhar na ação dos indivíduos é seguir os traços deixados pelos atores. Isto é, “[...] o que eles dizem e o que eles fazem, nos seus próprios termos." (Pereira, 2010, p. 49).

Assim, existem duas etapas que compõe o novo processo de tradução: 1) um: “o social desapareceu” (Latour, 2012, p. 157) e 2) "o social voltou como associação" (Latour, 2012, p. 159). Assim, os diferentes modos com que os atores estão associados pode fazê-los fazer outras coisas. Isso mostra que uma força não permanece da mesma forma por todo o percurso - como um intermediário - mas gera transformações fiéis diante dos numerosos eventos, desencadeados por outros mediadores que estão situados em toda a parte. Isso seria chamado o "princípio de irredução", que significa que “[...] a concatenação dos mediadores não traça as mesmas ligações e não requer o mesmo tipo de explicações como séquito de intermediários transportando uma causa" (Latour, 2012, p. 159). E, aqui, esbarra-se com a ideia de que o social deve ser explicado, em vez de fornecer explicação.

Contudo, para designar algo como social, entendendo este social não como uma força que respalda todos os atores, mas uma conexão que transporta transformações, transformando em tradução. Aqui, tradução significa "[...] uma relação que não transporta causalidade, mas induz dois mediadores à coexistência" (Latour, 2012, p. 159). Se uma causalidade 
parece ser transportada de um modo previsível e rotineiro, então ela é a prova de que outros mediadores foram mobilizados para tornar esse deslocamento simples e previsível.

Tradução, então, seria, quando se interfere de um objeto para outro da ação, uma translação de objetos. Assim pode-se chegar à conclusão que existem traduções entre mediadores que provocam associações possíveis de serem rastreáveis nesta possibilidade da dimensão artefatual da psique humana, pois qualquer trabalho assumido por um teórico da ANT deverá ampliar o repertório de atores, incluindo neste os objetos na gênese do processo da ação. Assim, “[...] o que Bruno Latour quer fazer recuperar, aqui, é a nossa capacidade de dar um passo a mais nas descrições, atentando-se ao esgotamento e aos muitos atuantes (actantes) desses eventos" (Segata, 2012, p. 240).

\section{Considerações Finais}

O estudo aqui apresentado pretendeu contribuir no sentido de apontar caminhos e direcionar ações para se pensar a Psicologia sob novos prismas, com a influência da Teoria Ator-Rede em seus preceitos teórico-metodológicos. Avaliando que a Psicologia tem a característica bastante singular de rever, comum a frequência bastante acelerada, as suas próprias categorias analíticas e os seus preceitos teórico-metodológicos, o trabalho despontou neste sentido, a fim de buscar rever categorias e princípios da Psicologia. No entanto, isso não é uma exclusividade desta área de conhecimento; trata-se de algo bastante comum às Ciências Humanas e, como se percebe, um desses momentos de questionamento de suas próprias bases, nos últimos anos, vem das reflexões levantadas pela perspectiva sociotécnica ou Teoria Ator-Rede de Bruno Latour.

Tendo em vista que as críticas que Bruno Latour faz, a partir da perspectiva sociotécnica da Teoria Ator-Rede, e que tem gerado efeitos no interior da Antropologia e da Sociologia, no que se refere ao modo como ambas tem pensado as associações entre humanos e não-humanos e utilizado termos como sociedade, cultura ou indivíduo, pressupõe-se que uma análise dessa natureza, com vistas à procura por contribuições à pesquisa em Psicologia, possa igualmente estabelecer tópicos para uma autocrítica. Isso se traduziria, grosseiramente, por fazer pensar em um tipo de pesquisa que considere as composições entre humanos e nãohumanos.

Por alto, isso não parece distante do que comumente se faz em termos de pesquisa em humanidades, mas basta uma revisão, ainda que superficial em alguns, para se notar que a ênfase está no sócio 
(entendido como o humano), onde são enfatizadas as formas de ajuntamento de pessoas, cuja maior parte das vezes deixa subentendido que aquilo que chamamos de relações sociais é algo que se estabelece exclusivamente entre humanos/pessoas. Assim esse sociotécnico assume a forma de um lugar técnico preenchido ou sustentador de relações sociais. Ora, também, o acento está no técnico (entendido como o nãohumano),e então é possível encontrar trabalhos contemporâneos que tratam da inovação tecnológica, enfatizando as potencialidades das máquinas e dos softwares, cuja maior parte das vezes deixa subentendido que o humano está para essas técnicas, como se elas exclusivamente determinassem novas modalidades de relação e constituição entre os humanos.

Enfim, tanto de uma forma como de outra, sócio e técnico aparecem como fenômenos distintos, mesmo que corriqueiramente tratados sob a égide de um único termo - o sociotécnico. E foi a partir dessa constatação que a Teoria do AtorRede possibilitou, e possibilita, subsídios para se dar um tratamento diferenciado aos temas das humanidades, pensando o sócio e o técnico constituídos simetricamente como uma rede que descentra agências na sua capacidade de tradução (constituição de híbridos). Nesse caminho, de modo amplo, o objetivo dessa pesquisa foi o de aproximar o pensamento da Teoria Ator-Rede à Psicologia, na busca do estabelecimento de tópicos para uma reflexão teóricometodológica, no que diz respeito à noção do tratamento das associações entre humanos e não-humanos em seus trabalhos. Sabe-se também que as matrizes curriculares dos cursos de Psicologia que encontramos, na maior parte das instituições, compreendem um período fixado em quatro a cinco anos, o que representa a maioria dos cursos das universidades brasileiras. Sendo a Psicologia uma área das ciências humanas, o que é disponibilizado graduação, geralmente é nada mais que uma pequena base de algumas teorias que fundamentam a ciência psicológica. E no caso da obra de Bruno Latour - a Teoria Ator-Rede trata-se de mais um desses casos que apenas os acadêmicos, que dão continuidade aos seus estudos, em nível de mestrado ou doutorado, é que acabarão tendo algum contato com ela.

Neste sentido, a pesquisa buscou demonstrar a importância de um aprofundamento na obra deste autor, com vistas a buscar contribuições para a Psicologia. Assim, o trabalho também fez lembrar a importância das revisões bibliográficas, que auxiliam na atualização de determinados assuntos, além de possibilitar que determinadas críticas 
importantes não passem despercebidas pelos profissionais da área, trazendo engrandecimento em termos de teoria, método e prática.

\section{Referências}

Arendt, R. J. (2006). O que nós psicólogos podemos aprender com a teoria ator-rede? Interações, v. 12(22), 57-86.

Arendt, R. J. (2010). Enfim: e a tua Psicologia, como é, e para quê? In: Ferreira, A. L., Freira, L. L., Moraes, M. e Arendt, R. J. Teoria Ator-Rede e Psicologia. (pp. 17-39). Rio de Janeiro: NAU.

Akrich, M. \& Latour, B. (1992). A summary of a convenient vocabulary of the semiotics for human and nonhuman assemblies. In: Bijker, W. e Law, J. (ed.). Shaping Technology, Building Society: studies in sociotechnical change (pp. 123-146). Cambridge, MIT Press.

Bijker, W. \& Pinch, T. (1989). The Social Construction of Facts and Artifacts: or how the Sociology of Science and Sociology of Technology might benefit each other. In: Bijker, W., Pinch, T. e Hughes, P. (ed.). The Social Construction of Technological Systems (pp. 17-50). Cambridge: MIT Press.

Bloor, D. (1999). Anti Latour. Studies in History and Philosophy of Sciences, v.30 (1), p.81112. doi.org/10.1016/S0039-3681(98)00038-7

Bloor, D. (2009) Conhecimento e Imaginário Social. São Paulo: Editora da Unesp.

Bonamigo, I. S. (2010). A Teoria Ator-Rede como dispositivo teórico-metodológico de análise da produção de violências na contemporaneidade. In: Ferreira, A. L., Freira, L. L., Moraes, M. e Arendt, R. J. Teoria Ator-Rede e Psicologia. (pp. 67-80). Rio de Janeiro: NAU.

Bruno, F. (2010). Prefácio. In: Ferreira, A. A. L.; Freira, Leticia de Luna; Moraes, M.; Arendt, R. J. Teoria Ator-Rede e Psicologia. (pp. 5-7). Rio de Janeiro: NAU.

Callon, M. (1989). Society in the Making: the study of technology as a tool for sociological analysis. In: Bijker, W., Pinch, T., Hughes, P. (ed.). The Social Construction of Technological Systems. (pp. 83-104). Cambridge: MIT Press.

Ferreira, A. L., L, L, Moraes, M. \& Arendt, R. (2010). Teoria Ator-rede e Psicologia. 1. ed. Rio de Janeiro: Nau Editora. doi.org/10.1590/S0102-37722010000500005

Freire, L. (2006). Seguindo Bruno Latour: notas para uma antropologia simétrica. Comum, v. 11(26), 46-65. 
Kuhn, T. (1962). A estrutura das revoluções cientificas. Chicago: editora Perspectivas.

Latour, B. (1999a). Factures/Fractures: from de concept of network to the concept of attachment. (pp. 20-36). Autumn.

Latour, B. (1999b). On Recalling ANT. In: Hassard, J. e Law, J. (ed.). Actor-Network-Theory and After. (pp. 15-25). Oxford: Blackwell. doi.org/10.1111/j.1467-954X.1999.tb03480.x

Latour, B. (2001a). A Esperança de Pandora: ensaios sobre a realidade dos estudos científicos. Bauru, Edusc.

Latour, B. (2001b). Le Métier de Chercheur Regard d'unAnthropologue. 2. ed. Paris: INRA Editions.

Latour, B. (2002). Reflexão Sobre o Culto Moderno dos Deuses Fe(i)tiches. Bauru: Edusc.

Latour, B. (2003). Un Monde Pluriel Mais Commun: entretiens avec François Ewald. Luxembourg: Éditions de L'Albe.

Latour, B. (2005). Jamais Fomos Modernos: ensaio de antropologia simétrica. São Paulo: Editora 34.

Latour, B. (2012). Reagregando o Social: uma introdução á teoria do ator-rede. Bauru: Edusc.

Latour, B. \& Woolgar, S. (2006). La Vie de Laboratoire: la production des faits scientifiques. Paris: La Découverte.

Law, J. (1999). After ANT: complexity, naming and topology. In: In: Hassard, J. e Law, J. (ed.). Actor-Network-Theory and After. (pp. 1-14). Oxford: Blackwell. doi.org/10.1111/j.1467954X.1999.tb03479.x

Law, J. (2004). After Method: mess in social science research. Londres: Routledge.

Law, J. (2006). Traduction/Trahison: notes on ANT. Convergencia, v.13(42), 47-72.

Moraes, M. (2005) A ciência como rede de atores: ressonâncias filosóficas. História,

Ciências e Saúde. v. 11(2), 321-333. doi.org/10.1590/S0104-59702004000200006

Pereira, H. (2010). Jung e o laboratório da alma: a psicologia analítica examinada pela teoria ator-rede. Curitiba: Juruá.

Rifiotis, T., Segata, J., Màximo, M. E. \& Cruz, F. G. (2011). Redes sociotécnicas: hibridismos e multiplicidade de agências na pesquisa da Cibercultura. In: Lacerda, J. e Barreto, V. (org.). Comunicação, Educação e Vivência: saberes e vivencias em teorias e pesquisa na América Latina. (pp. 236-265). João Pessoa: EDUFPB; EDUFRN.

Segata, J. (2012). Reagregando o Social: uma introdução á Teoria Ator-Rede. Ilha: revista de Antropologia, v. 14(1), 238-243. 
Skinner, B. F. (1974). Sobre o Behaviorismo. São Paulo: Cultrix.

Tsalis, A. C., Ferreira, A. A. L., Moraes, M. O. \& Arendt, R. J. O que nós psicólogos podemos aprender com a teoria ator-rede? Interações, 12(22), 57-86.

Ziemkendorf, M. (2007). Actor-Network Theory. Berlin: GRIN Verlag.

\section{A autora:}

Idonézia Collodel-Benetti é graduada em Letras e Psicologia, tem pós-graduação nas seguintes áreas: Psicopedagogia (especialização), Psicologia (Mestrado em Saúde, Família e Desenvolvimento Psicológico UFSC) e Letras Inglês (Mestrado em Estudos Linguísticos e Literários - UFSC) e Saúde Coletiva (Doutorado em Ciências Humanas e Políticas Públicas em Saúde/Saúde Mental - UFSC), e-mail: idonezia@ hotmail.com

João Paulo Roberti Junior é doutorando em Psicologia, pela Universidade Federal de Santa Catarina - UFSC, Florianópolis - SC.

Recebido em: 11/02/2018

Aprovado em: 30/12/2018 